\title{
A Mediated Moderation Model: Personality, Team Psychological Safety and Team Performance
}

\section{Tarman Budianto $\bowtie$}

Widyaiswara, Pusdiklat Pegawai Kemendikbud

(Personnel Education and Training Center, Indonesian Ministry of Education and Culture)

\begin{tabular}{l} 
Article Information \\
\hline Article History: \\
Received March 2021 \\
Approved March 2021 \\
Published March 2021 \\
\hline Keywords: \\
Personality, \\
Psychological Safety, \\
Team Performance, \\
Trait Activation Theory.
\end{tabular}

\section{INTRODUCTION}

Psychological safety is a concept that continues to evolve and become a concern of researchers over the past two decades. The study of Schein and Bennis (1965) about organizational change is a milestone in the emergence of psychological safety constructs. Schein and Bennis (1965) state that psychological safety is the degree to which individuals are confident and feel comfortable in facing changes that occur.

In the next stage, psychological safety was conceptualized by Kahn (1990) as an individual's perception of a sense of comfort performing. However, Edmondson (1999) argues that psychological safety is a climate at the team level and defines it as the trust of team members that the team does not have interpersonal risk. Edmondson's study (1999) became an important point in the development of psychological safety studies. Edmondson's conception (1999) became the most dominant reference for researchers in conducting psychological safety studies over the past two decades.
At present, the study of psychological safety has been carried out with various theoretical perspectives. The results of the review of Newman et al. (2017) classify two streams of theory in psychological safety studies. Both offer a positive perspective of psychological safety on performance. First, Social Learning Theory (Bandura, 1977) which is the basis of the research argument that psychological safety can be built by supporting workplaces, so that these conditions can affect learning (Ortega et al., 2010; Bstieler \& Hemmert, 2010), performance (Kostopoulos \& Bozionelos, 2011; Huang \& Jiang, 2012; Ortega et al., 2014), innovation (Post, 2012; Gu et al., 2013), and creativity (Palanski \& Vogelgesang 2011). Psychological safety can be a predictor of performance, both directly and indirectly. Psychological safety is an indirect predictor of performance through facilitating information sharing, seeking feedback, and experimentation (for example, Carmeli, 2007; Liu et al., 2014). This study refers to the results of the study of Li and Tan, (2012) and Li and Yan (2009) which show that psychological safety can be a direct predictor of performance.

(C) 2021 Universitas Negeri Semarang

$\triangle$ Correspondence Address:

e-ISSN 2502-1451

Pusdiklat Pegawai Kemendikbud, J1. Ciputat Parung KM 19, Serua, Bojongsari, Depok, Jawa Barat

Email: tarman_060708@yahoo.com 
Second, the social exchange theory that underlies the study that the quality of strong relationships in the workplace can improve psychological safety and direct employees to compensate (exchange processes) with positive forms of work (De Clercq \& Rius, 2007; Chen et al., 2014) Meanwhile, organizational members are individuals who have different personalities from one another. The scheme of the relationship between personality, team psychological safety and team performance is still not well developed. Newman et al. (2017) identified antecedent factors of team psychological safety include (1) leadership behavior (for example: leadership support (Roberto, 2002) and leadership trust (Li \& Tan, 2012), (2) network relationships (for example: the quality of social relationships (Gu et al., 2013) and the nature of team membership (Burris et al., 2009), as well as (3) team characteristics (for example: characteristics of team competition (Chen \& Tjosvold, 2010) and the formal structure of the team (Bresman \& Zellmer-Bruhn, 2013).

This review of the team's psychological safety antecedent's literature suggests that individual factors of team members have not been explored. In fact, the personality composition of team members has a strong influence on team dynamics (Humphery et al., 2011). Radović et al. (2020) emphasized that understanding individuals in team dynamics can trigger organizations to function optimally in managing human potential. This further reinforces that the individual factors of team members as antecedents need to be studied as an effort to develop a psychological safety. The theory that specifically discusses personality traits in workplace situations is the trait activation theory (TAT) (Tett \& Guterman, 2000). TAT describes the relationship between personality traits and work context situations with the activation mechanism of personality traits (Tett \& Burnett, 2003).

Personality is described as all patterns of individual behavior. Funder (2001) states that the study of personality has progressed until the model of "The Big Five Personality" has emerged which is now widely accepted by academics: which includes; Emotional Stability, Conscientiousness, Agreeableness, Extraversion, and Openness. Personality studies to predict performance have been carried out in various perspectives (Penney et el. (2011). Initially, the results of the study Guion and Gottier (1965) concluded that performance cannot be predicted by personality tests. However, in its development academics argue that personality can predict performance (Hogan, 2005; Judge \& Zapata, 2015).
Regarding personality and performance, Judge and Zapata (2015) have investigated the activation of personality and performance. His research results show that the expression of behavior of a personality activated by a specific context can improve performance (Judge \& Zapata, 2015). Meanwhile, the results of the study of $\mathrm{Li}$ and Yan (2009) and Li and Tan (2012) show that psychological safety can be a direct predictor of performance. This study proposes specific context moderating effects that activate personality (individual level) mediated by the psychological safety of the team in predicting team performance. The study is an important foundation in parsing and filling in the personality interaction gap, team psychological safety and team performance.

Activated personality will build the psychological safety of the team and can ultimately improve team performance. This study deepens the results of the study of Judge and $\mathrm{Za}$ pata (2015) by proposing a mediated moderation model. Psychological safety mediates the tendency of individuals to act proactively and improve performance in Conscientiousness, Extraversion and Opennes personality (Newman, et al, 2017). This will lead them to express their activated personality, so that the level of psychological safety becomes high. Therefore, a more in-depth study and investigation of the relationship between the personality and psychological safety of the team is needed to predict team performance.

\section{Personality, Team Psychological Safety \& Team Performance}

In the field of organizational psychology, personality has an important role (Barrick et al., 2001). One theory that explains personality and its relation to performance is TAT. TAT provides a good theoretical basis in determining the category of situational traits that moderate the validity of personality traits (Tett \& Burnett, 2003). This theory is built on the argument that various situations in each personality will have a different effect (Ekehammar, 1974; Tett \& Guterman, 2000). Tett and Burnett (2003) have applied this perspective to the relationship between personality and performance in a work context. Thus, situations can operate on the activation of personality traits.

Personality is the dominant construct in psychology (Phares \& Chaplin, 1997). The relevance of situations and personality traits can encourage (activate) the expression of personality traits (Tett \& Burnett, 2003) so that they can build interpersonal trust and timpun members do not hesitate to be themselves in expressing their 
personality traits. This condition can reduce interpersonal risk in the team. This condition is also relevant to team psychological safety, as a shared belief that the team is safe from interpersonal risks (Edmondson, 1999). In the high team psychological safety, team members feel safe to convey ideas, provide honest feedback, collaborate, and experiment in working on team tasks (Edmondson \& Lei, 2014). Thus, the process of activating the personality traits of the team is thought to increase team psychological safety.

Based on The Big Five Personality and TAT, Judge and Zapata (2015) conducted a study of the activation of personality and performance. Identified several specific situations that can activate five personalities which include: (a) work that requires freedom (For example: Anthropologist, Taxi driver, Marketing manager), (b) work with high attention-detail requirements (for example: Air traffic controller, Accountant / auditor, Legal secretary), (c) work that requires high social skills (for example: Clergy, Counseling psychologist, Concierge), (d) work with a high level of competition requirements (for example: Coach / scout, Financial manager, Advertising sales manager), (e) work where a person must often deal with unpleasant responses (for example: Correctional officers, Telemarketers, Flight attendants) and (f) jobs with high innovation requirements (for example: Actor, Systems analyst, Materials scientist). Judge and Zapata (2015) state that each activated (conscientiousness, emotional stability, extraversion, agreeableness, and openness) will improve performance. However, this study argues that this process of improving performance will occur when realized through the team psychological safety. High psychological safety can improve performance (Li \& Yan, 2009; Li \& Tan, 2012). Individuals who feel the level of psychological safety of high teams tend to experiment and explore in their work (Li \& Tan, 2012). This behavior can ultimately help the team achieve better performance by improving quality and work efficiency. This study propose that an activated personality will build the psychological safety of the team and ultimately improve team performance. Team psychological safety mediates the effects of specific context moderation (trait activation) on the relationship of personality and team performance.

The psychological safety of the team becomes a mediating variable on the personality relationship that is activated by the specific context and team performance. Personality is an individual level construct. Through this model, this study proposes a cross-level study of psychological safety. Walumbwa and Schaubroeck (2009) have conducted psychological safety studies at the team level and their influence at the individual level. Meanwhile, Liu et al. (2014) conducted a study of the interaction of individual variables on team level psychological safety to predict team performance. Referring to these empirical studies, this study proposes personalities at the individual level that are activated by specific contexts that can predict psychological safety at the team level and team performance.

Based on the review of Newman et al (2017), there are three personalities directly related to psychological safety which include: conscientiousness, extraversion and opennes.This personality directs them to be more likely to give signs and opportunities to express their personalities that are activated in certain contexts, so that the level of psychological safety becomes high (Newman et al. 2017). Referring to this review, this study proposes three personalities formulated in the model.

\section{Conscientiousness Personality}

Conscientiousness personalities tend to be more careful in carrying out an action or considerate in making a decision, they also have high self-discipline. Specifically, conscientiousness works very well in jobs that require freedom, because conscientious individuals are often ambitious (Goldberg, 1993) and achievement oriented (Costa \& McCrae, 1992). So it is not surprising, if individuals who have conscientiousness naturally behave consistently with well-organized / systematic tendencies. The study of Hmel and Pincus (2002) states that individuals who pursue achievement tend to be focused and self-regulating, so individuals who work independently will strengthen the positive effects of seriousness on performance. This study agrees with the results of the Judge and Zapata (2015) study that work that requires freedom can activate conscientiousness. In other words, conscientiousness personality will be activated in the context of work situations that require freedom, so this condition will make individuals feel psychologically safety.

In another dimension, conscientiousness can also be activated with another specific context. Research Barrick et al. (1993) found that employees with a conscientiousness personality can set specific work goals and show more commitment to these goals. The study results of Jackson et al. (2010) found that conscientiousness individuals were more likely to use a neat and systematic document filing system, even recording important work dates and daily activities 
in detail. Referring to the results of the research, individuals with conscientiousness personality will tend to be activated in work with high attention-detail requirements. This study agrees with the results of the Judge and Zapata (2015) study that work with high attention-detail requirements can activate conscientiousness. In other words, conscientiousness personality will be activated in the context of the work situation with high attention-detail requirements so that it can build psychological safety.

The psychological safety of the team that builds from an activated personality can affect team performance. This is relevant to the review of Newman et al. (2017) which states that team traversion personality (Riggio, 1986). Individuals with extraversion personality are more likely to like to be involved in social activities (Argyle $\& \mathrm{Lu}, 1990)$, even according to Ashton et al. (2002) they are also more likely to enjoy social activities. This study has the same view with the results of Judge and Zapata (2015) that work that requires high social skills can activate extraversion personality. Referring to these findings, extraversion personality will be activated in the context of work situations that require high social skills, so that this condition will make the individual extraversion feel psychologically safety.

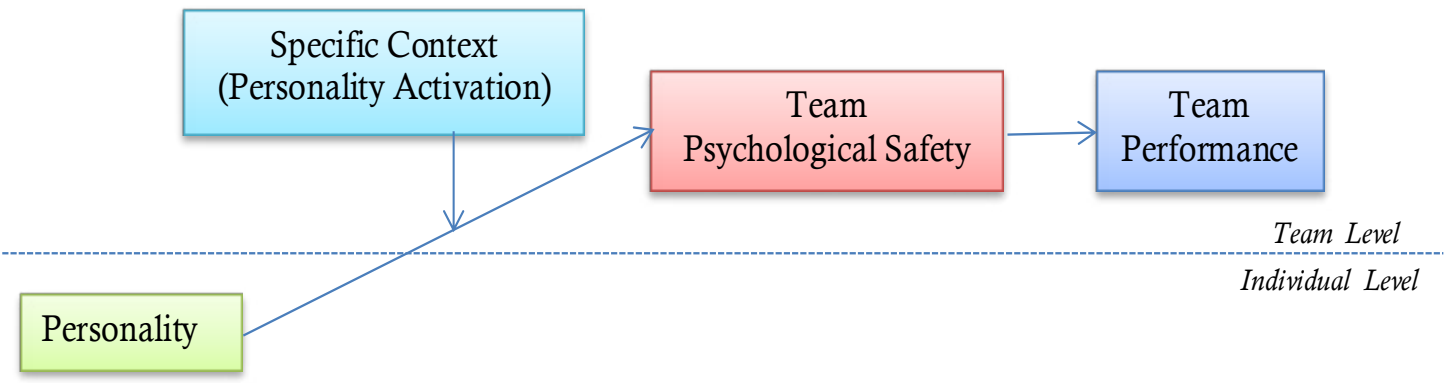

Figure 1. A Mediated Moderation Model: Personality, Team Psychological Safety and Team Performance

psychological safety can be a predictor of performance. Individuals who feel the level of psychological safety of a high team have a tendency to experiment and explore work (Li \& Tan, 2012). Based on this, it can be proposed that:

\section{Proposition 1:}

Team psychological safety will mediate the moderating effect of (a) work that requires freedom and (b) work with high attention-detail requirements on the relationship of Conscientiousness personality and team performance. In particular, the indirect effects of Conscientiousness personality on team performance through psychological safety will be stronger in (a) work that requires freedom and (b) work with high attention-detail requirements.

\section{Extraversion personality}

Extraversion personality is related to someone's comfort level in interacting with others. Extraversion is the level of intensity of social interactions related to individual self-confidence (McCrae \& Costa, 1987). Good social and emotional expressions, high emotional sensitivity, and social and emotional control abilities are the characteristics of individuals who have ex-
In another dimension, the results of laboratory studies Graziano et al. (1985) showed that personality extraverts considered competitive games more attractive and more interesting than cooperative games. The results of the second study reflect the first; that is, that extraversion is considered a competitive game as more friendly and pleasant (Graziano et al., 1985). This is reinforced by the literature which shows that extravert individuals enjoy competition (Graziano et al. 1985; Kirkcaldy \& Furnham, 1991) and even excel in competitive environments (Bentea \& Anghelache, 2012). In other words, extravers tend to perform better in competitive environments (Bentea \& Anghelache, 2012). This study also agrees with the results of the study of Judge and Zapata (2015) which states that work with a high level of competition requirements can activate the extraversion personality. In other words, extraversion personality will be activated in the context of work situations with a high level of competition requirements, so that this condition will make the individual extraversion feel psychologically safety.

Individual characteristics of extraversion are happy to socialize, easy to socialize, live in groups and be firm. Gallagher (1990) states 
that individuals with extraversion personalities respond to work pressure as a challenge, so that they can overcome stressful social situations. The study of Graziano et al. (1985) also shows that extraverts can see the positive side of a social interaction. Extraversion is very skilled in handling problems that require social interaction such as dealing with people who are unpleasant or angry (Tett \& Burnett, 2003). This is reinforced by the results of Judge and Zapata (2015) who stated that work in which a person must often deal with unpleasant responses can activate the extraversion personality.

With these findings, the specific context is work that requires strong social skills, competitive work, and work in which a person must often deal with unpleasant responses can activate the extraversion personality. Activation of extraversion personality in a specific context will build the psychological safety of the team. Individuals who feel the level of psychological safety of a high team have a tendency to experiment and explore work (Li \& Tan, 2012). This behavior can ultimately help the team achieve better performance by improving quality or work efficiency. Therefore, it can be proposed that:

\section{Proposition 2:}

Team Psychological Safety will mediate the moderating effect (a) work that requires high social skills, (b) work with a high level of competition requirements, and (c) work where a person must often deal with unpleasant responses on the relationship of extraversion personality and Team performance. In particular, the indirect effects of extraversion personality on Team performance will be stronger in (a) jobs that require high social skills, (b) jobs with a high level of competition requirements, and (c) work where someone must often deal with unpleasant responses.

\section{Openness personality}

His interest in new things and the desire to learn something new are the characteristics of individuals with an openness personality. Individuals who have the personality of oppenes are very imaginative, open minded, intellectual, creative and like new things, and have a broad perspective on differences (Costa \& McCrae, 1992; Johnson \& Ostendorf, 1993). Hmel and Pincus (2002) found that all aspects of openness to experience are associated with a tendency to self-regulate. In particular, Koestner and Losier (1996) state that openness is associated with reactive autonomy, ie orientation to act independently in work. Regarding Opennes personality, this study agrees with the results of the study of Judge and Zapata (2015) which states that work that requires freedom can activate the extraversion personality. In other words, Openness personality tends to be activated in specific situations in the form of work that requires freedom, so this condition will make individuals openness feel psychologically safety.

Positive characteristics of openness are tended to be more creative, imaginative, intellectual, curious and broad-minded. McCrae (1987) presents that all aspects of openness to experience are positively related to different creativity and thinking. Openness individuals are motivated to expand their experience with various breakthroughs that are made. Openness to experience is a catalyst that leads to expression and creative exploration (King et al., 1996). In fact, the performance of openness individuals is the most superior in work that requires creativity and innovation (for example, McCrae, 1987; King et al., 1996; Raja \& Johns, 2010). This study agrees with the results of the study of Judge and Zapata (2015) which states that work with high innovation requirements can activate an openness personality. In other words, openness personality will be activated in the context of work situations with high innovation requirements, so that this condition will make openness individuals feel psychologically safety.

The team sychological safety that was built because the activation process of openness personality can affect team performance. This is relevant to the review of Newman et al (2017) which states that team psychological safety can be a predictor of performance. Individuals who feel the level of psychological safety of a high team have a tendency to experiment and explore work (Li \& Tan, 2012). This behavior can ultimately help the team achieve better performance by improving quality or work efficiency. Based on this, it can be proposed that:

\section{Proposition 3:}

Team Psychological Safety will mediate the moderating effect of (a) work that requires freedom and (b) work with high innovation requirements on the relationship of openness personality and team performance. In particular, the indirect effects of openness personality on Team performance will be stronger in (a) work that requires freedom and (b) work with high innovation requirements. 


\section{RESULT AND DISCUSSION}

Theoretical development and future directions

The purpose of this article is to develop a framework for mediating the team psychological safety on the personality and team performance. Literature shows that the psychological safety of the team is important to the team performance. Meanwhile, organizational members are individuals who have different personalities from one another. However, the interaction between personality, the psychological safety of the team and the performance of the team is still unexplored so that it becomes a gap that needs attention. This paper develops and present a mediated moderation model to parse the gap.

This model has several theoretical contributions to the literature. First, this study expands the literature on the relationship of personality and performance with the team's psychological safety as its mediation. Judge and Zapata (2015) have presented interactions of personality and performance variables. This study propose that the psychological safety of the team mediates the effects of specific context moderation on personality relationships (individual level) and team performance. This article summarizes and integrate the literature and point to the direction for future research regarding team psychological safety, personality and team performance. The model of this study also presents an answer to Newman et al (2017) review of the importance of a study of personality interactions and psychological safety.

Second, expanding the study of psychological safety on cross-levels. Walumbwa and Schaubroeck (2009) have conducted psychological safety studies at the team level and their influence at the individual level. Meanwhile, Liu et al. (2014) conducted a study of the interaction of individual variables on team level psychological safety, to predict team performance. This paper proposes personalities at the individual level that are activated by specific contexts that can predict psychological safety at the team level and team performance. Overall, it is hoped that the model proposed in this paper can be a framework for future research related to the assessment of team psychological safety, personality and team performance.

\section{Practical implications}

The main practical implication in management practices from this discussion is that, team psychological safety is a variable that needs to be considered in improving team performance. The psychological safety of the team can be built from the accuracy of employee recruitment or placement by paying attention to the personality and specific context of the work. Employees with conscientiousness personality will contribute optimally to team performance when recruited /placed in (a) jobs that require freedom and (b) work with high attention-detail requirements. Employees with extraversion personality will make optimal contributions to team performance when recruited / placed in (a) jobs that require high social skills, (b) jobs with a high level of competition requirements, and (c) jobs where someone must often deal with unpleasant response. Employees with openness personality will make optimal contributions to team performance when recruited / placed in (a) jobs that require freedom and (b) work with high innovation requirements. This happens because there is a process of activating the employee's personality with a specific context, so that it will build the psychological safety of the team and ultimately improve team performance.

\section{CONCLUSION AND RECOMMENDATION}

Personality has an important role in predicting performance (Barrick et al., 2001). Meanwhile, liturgy has also shown that team psychological safety is an important predictor of team performance (Newman et al 2017). The literature gap about personality interactions, team psychological safety and performance signals the importance of theoretical studies and empirical evidence to integrate these various variables. Based on TAT and The Big Five Personality this study formulated a specific context moderation role model (as personality activation) that mediated the psychological safety of the team to predict team performance. This paper aim is to facilitate empirical research by providing testable propositions. This study encourages researchers to continue to investigate the role of personality and psychological safety of the team to be a predictor of team performance so that it can become an organizational reference material in improving organizational performance.

\section{REFERENCES}

Argyle, M., \& Lu, L. (1990). Happiness and social skills. Personality and Individual Differences, 11; 1255-1261.

Ashton, M. C., Lee, K., \& Paunonen, S. V. (2002). What is the central feature of extraversion? Social attention versus reward sensitivity. Journal of Personality and Social Psychology, 83, 245-251. 
Bandura, A. (1977). Social learning theory. Englewood Cliffs, NJ: Prentice-Hall.

Barrick, M. R., Mount, M. K., \& Strauss, J. P. (1993). Conscientiousness and performance of sales representatives: Test of the mediating effects of goal setting. Journal of Applied Psychology, 78, $715-722$.

Barrick, M. R., Mount, M. K., \& Judge, T. A. (2001). Personality and performance at the beginning of the new millennium: What do we know and where do we go next? International Journal of Selection and Assessment, 9, 9-30.

Bentea, C. C., \& Anghelache, V. (2012). Comparative aspects concerning the effects of extraversion on performance in a cognitive task in competitive and cooperative environments. Procedia: Social and Behavioral Sciences, 33, 558-562.

Bresman, H., \& Zellmer-Bruhn, M. (2013). The structural context of team learning: Effects of organizational and team structure on internal and external learning. Organization Science, 24, $1120-1139$.

Bstieler, L., \& Hemmert, M. (2010). Increasing learning and time efficiency in interorganizational new product development teams. Journal of Product Innovation Management, 27, 485-499.

Burris, E. R., Rodgers, M. S., Mannix, E. A., Hendron, M. G., \& Oldroyd, J. B. (2009). Playing favorites: The influence of leaders' inner circle on group processes and performance. Personality and Social Psychology Bulletin, 35, 1244-1257.

Carmeli, A. (2007). Social capital, psychological safety and learning behaviours from failure in organisations. Long Range Planning, 40, 30-44.

Chen, C., Liao, J., \& Wen, P. (2014). Why does formal mentoring matter? The mediating role of psychological safety and the moderating role of power distance orientation in the Chinese context. International Journal of Human Resource Management, 25, 1112-1130.

Chen, G., \& Tjosvold, D. (2010). Shared rewards and goal interdependence for psychological safety among departments in China. Asia Pacific Journal of Management, 29, 433-452.

Costa, P. T., \& McCrae, R. R. (1992). Four ways five factors are basic. Personality and individual differences, 13(6), 653-665.

De Clercq, D., \& Rius, I. B. (2007). Organizational commitment in Mexican small and mediumsized firms: The role of work status, organizational climate, and entrepreneurial orientation. Journal of Small Business Management, 45 , 467-490.

Edmondson, A. (1999). Psychological safety and learning behavior in work teams. Administrative Science Quarterly, 44, 350-383.

Ekehammar, B. (1974). Interactionism in personality from a historical perspective. Psychological Bulletin, 81, 1026-1048.

Funder, D. C. (2001). Personality. Annual Review of Psychology, 52, 197-221.

Gallagher, D. J. (1990). Extraversion, neuroticism and appraisal of stressful academic events. Personality and Individual Differences, 11: 1053-1057.

Goldberg, L. R. (1993). The structure of phenotypic personality traits. The American Psychologist, 48, 26-34.

Graziano, W. G., Feldesman, A. B., \& Rahe, D. F. (1985). Extraversion, social cognition, and the salience of aversiveness in social encounters. Journal of Personality and Social Psychology, 49, 971-980.

Gu, Q., Wang, G. G., \& Wang, L. (2013). Social capital and innovation in R\&D teams: The mediating roles of psychological safety and learning from mistakes. $R \& D$ Management, 43, 89-102.

Guion, R. M., \& Gottier, R. F. (1965). Validity of personality measures in personnel selection. Personnel Psychology, 18, 135-164.

Hmel, B. A., \& Pincus, A. L. (2002). The meaning of autonomy: On and beyond the interpersonal circumplex. Journal of Personality, 70: 277-310.

Hogan, R. (2005). In defense of personality measurement: New wine for old whiners. Human Performance, 18, 331-341.

Huang, C. C., \& Jiang, P. C. (2012). Exploring the psychological safety of R\&D teams: An empirical analysis in Taiwan. Journal of Management \& Organization, 18, 175-192.

Humphrey, S. E., Hollenbeck, J. R., Meyer, C. J., \& Ilgen, D. R. (2011). Trait configurations in selfmanaged teams: A conceptual examination of the use of seeding for maximizing and minimizing trait variance in teams. Journal of $A p$ plied Psychology, 92, 885-892.

Jackson, J. J., Wood, D., Bogg, T., Walton, K. E., Harms, P. D., \& Roberts, B. W. (2010). What do conscientious people do? Development and validation of the Behavioral Indicators of Conscientiousness (BIC). Journal of Research in Personality, 44: 501-511.

Johnson, J. A., \& Ostendorf, F. (1993). Clarification of the five-factor model with the abridged big fivedimensional circumplex. Journal of personality and social psychology, 65(3), 563.

Judge, T. A., \& Zapata C.P., (2015). The personsituation debate revisited: Effect of situation strength and trait activation on the validity of the big five personality traits in predicting job performance, Academy of Management Journal, 58, (4), 1149-1179.

Kahn, W. A. (1990). Psychological conditions of personal engagement and disengagement at work. Academy of Management Journal, 33, 692-724.

King, L. A., Walker, L. M., \& Broyles, S. J. (1996). Creativity and the five-factor model. Journal of Research in Personality, 30, 189-203.

Kirkcaldy, B., \& Furnham, A. (1991). Extraversion, neuroticism, psychoticism and recreational choice. Personality and Individual Differences, 12, 737-745.

Koestner, R., \& Losier, G. F. (1996). Distinguishing reactive versus reflective autonomy. Journal of Personality, 64, 465-494. 
Kostopoulos, K. S., \& Bozionelos, N. (2011). Teamexploratory and exploitative learning: Psychological safety, task conflict, and teamperformance. Group \& Organization Management, 36, 385-415.

Li, A. N., \& Tan, H. H. (2012). What happens when you trust your supervisor? Mediators of individual performance in trust relationships. Journal of Organizational Behavior, 34, 407-425.

Li, N., \& Yan, J. (2009). The effects of trust climate on individual performance. Frontiers of Business Research in China, 3, 27-49.

Liu, S., Hu, J., Li, Y., Wang, Z., \& Lin, X. (2014). Examining the cross-level relationship between shared leadership and learning in teams: Evidence from China. The Leadership Quarterly, 25, 282-295.

McCrae, R. R. (1987). Creativity, divergent thinking, and openness to experience. Journal of Personality and Social Psychology, 52, 1258-1265

McCrae, R. R., \& Costa, P. T. (1987). Validation of the five-factor model of personality across instruments and observers. Journal of personality and social psychology, 52(1), 81.

Newman, A., Donohueb, R., \& Eva, N., (2017). Psychological safety: A systematic review of the literature, Human Resource Management Review, 27, 521-535

Ortega, A., Sanchez-Manzanares, M., Gil, F., \& Rico, R. (2010). Team learning and effectiveness in virtual project teams: The role of beliefs about interpersonal context. Spanish Journal of Psychology, 13, 267-276.

Ortega, A., Van den Bossche, P., Sanchez-Manzanares, M., Rico, R., \& Gil, F. (2014). The influence of change-oriented leadership and psychological safety on team learning in healthcare teams. Journal of Business and Psychology, 29, 311-321.

Palanski, M. E., \& Vogelgesang, G. R. (2011). Virtuous creativity: The effects of leader behavioural integrity on follower creative thinking and risk taking. Canadian Journal of Administrative Sciences, 28, 259-269.
Penney, L. M., Emily David, L.A. Witt (2011). A review of personality and performance: Identifying boundaries, contingencies, and future research directions, Human Resource Management Review, 21, 297-310.

Post, C. (2012). Deep-level teamcomposition and innovation: Themediating roles of psychological safety and cooperative learning. Group \& Organization Management, 37, 555-585.

Radović, S., Sladojević Matić, J., \& Opačić, G. (2020). Personality traits composition and team performance. Journal Of Sustainable Business And Management Solutions In Emerging Economies, 35 (2), $18-42$

Raja, U., \& Johns, G. (2010). The joint effects of personality and job scope on in-role performance, citizenship behavior and creativity. Human Relations, 20, 1-25.

Riggio, R. E. 1986. Assessment of basic social skills. Journal of Personality and Social Psychology, 51: 649-660.

Roberto, M. A. (2002). Lessons from Everest: The interaction of cognitive bias, psychological safety and system complexity. California Management Review, 45, 136-158.

Schein, E. H., \& Bennis, W. (1965). Personal and organizational change through group methods. New York: Wiley.

Tett, R. P., \& Guterman, H. A. (2000). Situation trait relevance, trait expression, and cross situational consistency: Testing a principle of trait activation. Journal of Research in Personality, 34, 397423.

Tett, R., \& Burnett, D. (2003). A personality trait-based interactionist model of job performance. Journal of Applied Psychology, 88, 500-517.

Walumbwa, F. O., \& Schaubroeck, J. (2009). Leader personality traits and employee voice behavior: Mediating roles of ethical leadership and work group psychological safety. Journal of Applied Psychology, 94, 1275-1286. 